\title{
Erratum to: Investigation of inverter-based losses and magnet-temperatures of a 1 MVA permanent magnet synchronous generator via a 25 kVA physical model
}

B. Weiss OVE, H. Polt, C. Geschrey OVE, M. Schroedl OVE

Published online January 27, 2015

(c) Springer Verlag Wien 2015

Erratum to: Elektrotechnik \& Informationstechnik DOI 10.1007/s00502-014-0274-1

Unfortunately, an error occurred in Fig. 2. The corrected Fig. 2 is given below.

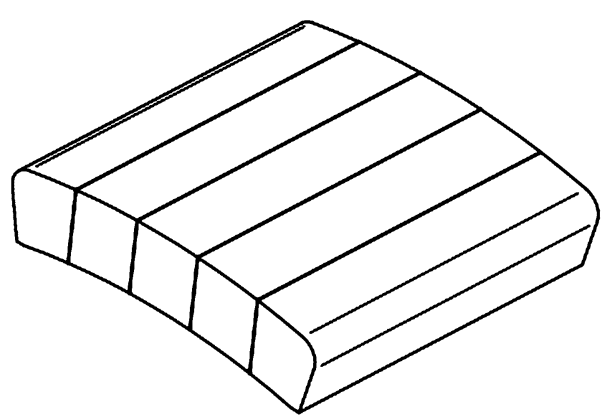

Fig. 2. Segmented surface mounted magnet

The online version of the original article can be found under doi:10.1007/s00502-014-0274-1.

Weiss, Bernhard, Institute of Energy Systems and Electrical Drives, Vienna University of Technology, Gusshausstrasse 25-29, 1040 Vienna, Austria

(E-mail: bernhard.weiss@tuwien.ac.at); Polt, Harald, Institute of Energy Systems and Electrical Drives, Vienna University of Technology, Gusshausstrasse 25-29, 1040 Vienna, Austria; Geschrey, Christoph, Institute of Energy Systems and Electrical Drives, Vienna University of Technology, Gusshausstrasse 25-29, 1040 Vienna, Austria; Schroedl, Manfred, Institute of Energy Systems and Electrical Drives, Vienna University of

Technology, Gusshausstrasse 25-29, 1040 Vienna, Austria 